\title{
Factors Associated with Non-Adherence to Antihypertensive Medication among Hypertensive Patients in Community
}

\author{
Tirtha Man Shrestha ${ }^{1}$, Laxman Bhusal ${ }^{1}$, Shankar Raut ${ }^{1}$, Rajan Ghimire ${ }^{1}$, Poonam Shrestha ${ }^{2}$
}

${ }^{1}$ Department of General Practice and Emergency Medicine, Maharajgunj Medical Campus, Tribhuwan University, Nepal

${ }^{2}$ Nepal Eye Hospital, Tripureshwor, Kathmandu, Nepal

\section{Corresponding Author:}

Dr. Tirtha Man Shrestha

Email: tirtha_48@yahoo.com.au

\section{Access this article online}

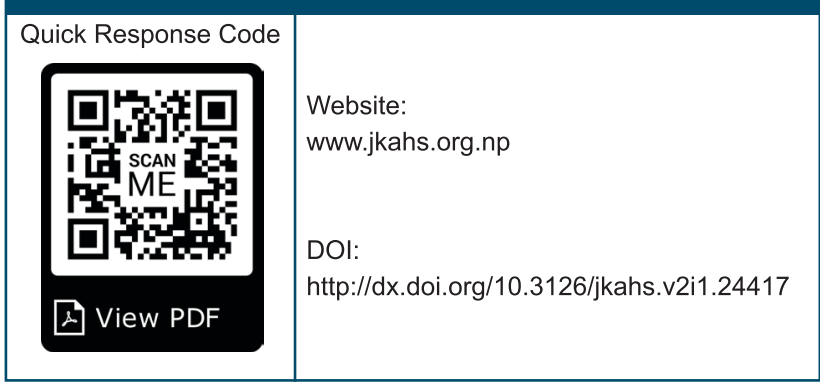

\section{ABSTRACT}

Background: Hypertension is one of the common non-communicable health problems. While pharmacologic intervention is the most efficient way to control hypertension; non-adherence to medication is accounted as a significant cause for complications. This study was to address and to determine the magnitude of non-adherence among hypertensive patients by summarizing the associated risks factors among patients in the community level.

Method: This is a cross-sectional study conducted on hypertensive patients who visited the community health clinic at Dhading, Nepal on 9th and 10th June 2018 using a pre-structured questionnaire. Patients were sampled by nonprobability purposive sampling method. Effect of age, gender, marital status, employment, education level, presence of diabetes, cerebrovascular disease, current smoker, and family history of hypertension were analyzed by the compliance of antihypertensive drugs using frequency distribution, chi-square test, and logistic regression. For all of the analysis p-value $<0.5$ was considered as significant.

Results: 150 patients were included in the study, out of whom 48 patients were found adherent and 102 patients non-adherent to antihypertensive medication. Out of total population $46 \%(n=69)$ were male and 54\% ( $\mathrm{n}=81)$ were female with no significant association between compliant and noncompliant groups $(\mathrm{OR}=1.599, \mathrm{p}>0.05)$. Mean age of patients in complaint group was 57 years and in the non-compliant group was 52 years with an odds ratio of 0.96 ( $p<0.05,95 \%$ C.I : $0.933-0.987)$. However, there was no significant effect of marital status, employment status, and family history of hypertension on adherence to antihypertensive medication. Presence of diabetes had a significant effect on adherence to medication $(\mathrm{OR}=2.634, \mathrm{p}<0.05)$. The most common reason for non-adherence was the fear of getting stuck with medication for lifetime $(\mathrm{n}=31,30.3 \%)$ followed by the use of ayurvedic/ home remedy $(n=27,26.5 \%)$, unaware of complications $(n=16,15.7 \%)$, lifestyle modification $(n=14$, $13.7 \%)$, and financial weakness $(\mathrm{n}=9,8.8 \%)$. 
Conclusion: Fear of taking medication lifelong was the major reason for non-adherence; however, age and comorbid health conditions like diabetes have a significant effect on adherence to medication. Health care awareness and counselling can help these patients to overcome the fear of taking medication for a lifetime, which can increase the medication compliance rate.

Keywords: Hypertension, Medication, Non-adherence, Compliant, Noncompliant

\section{INTRODUCTION}

Hypertension (high blood pressure) is defined as systolic blood pressure greater than $140 \mathrm{mmHg}$ or diastolic blood pressure greater than $90 \mathrm{mmHg}{ }^{1}$ Blood pressure is the force of blood pushing against the walls of the arteries that carry blood from your heart to other parts of the body. ${ }^{2}$ Hypertension is one of the most prominent health problems in Nepal and across the globe. Different studies conducted in Nepal have shown that at least $30 \%$ of the sampled populations were suffering from the problem. ${ }^{3,4}$ World Health Organization (WHO) estimates that hypertension causes about $12.8 \%$ deaths of all deaths in the world. ${ }^{5}$ Incidence of hypertension is increasing every day. In United States of America, one third of the population is estimated to have high blood pressure. ${ }^{6}$ In United States $47.5 \%$ do not have controlled high blood pressure. ${ }^{6}$ Hypertension is the major risks factor for cardiovascular and cerebrovascular disease, which was 10th leading cause of death in Korea in 2015 and 9th leading cause of death in $2016 .^{7}$

Hypertension has been related to a wide range of risk from stroke, peripheral vascular disease, chronic kidney disease to eye damage. ${ }^{8}$ Raised blood pressure is also a major risk factor for coronary heart disease and ischemic as well as hemorrhagic stroke. ${ }^{5}$ If hypertension is left untreated it can lead to death. Hypertension can easily be controlled if followed proper treatment plan. About $20 \%$ of patients with hypertension have followed their treatment plan well enough to improve, and up to $25 \%$ of patients fail to even fill their initial prescription ${ }^{9}$. Right dosage of antihypertensive drugs can help control high blood pressure. Some other ways to control hypertension are daily habits such as exercises and diet. One of the effective ways to prevent cardiovascular and cerebrovascular disease could be hypertension control $^{10}$
It is very crucial that patient stick to the treatment plan in order to control high blood pressure. Medication adherence is defined as extent to which patients take medications as prescribed by health care providers. Intentional non-adherence is defined as active process whereby the patient chooses to deviate from treatment regimen whereas unintentional as passive process in which the patient may be careless or forgetful about adhering to treatment regimen. ${ }^{11,12}$ Adherence to a medications regimen can not only treat hypertension but also prevent adverse outcomes related to hypertension. Given the broad scope of the problem, ever increasing attention has devoted to identifying factors which contribute to noncompliance. ${ }^{13}$ According to the WHO, "increasing the effectiveness of adherence interventions may have far greater impact on the health of the population than any improvement in specific medical treatments." 14 This study's aim is to address the magnitude of the problem of non-adherence to antihypertensive drugs in hypertensive patients and the factors associated with non-adherence.

\section{METHODS}

A cross sectional survey was conducted on hypertensive patients who attended hypertensive general health camp in Dhading district of Nepal on 9th and 10th June 2018. The Survey questionnaire was constructed after reviewing the literature on the topic, which included age, sex, marital status, employment, comorbidity, and reason behind not taking medications. 


\section{Table 1: Hypertension classification as per Joint National Committee (JNC) 7 report 15}

\begin{tabular}{ccc}
\hline Blood Pressure & Systolic Blood Pressure & Diastolic Blood Pressure \\
\hline Normal & $<120 \mathrm{mmHg}$ & $<80 \mathrm{mmHg}$ \\
Prehypertension & $120-139 \mathrm{mmHg}$ & $80-89 \mathrm{mmHg}$ \\
Stage 1 hypertension & $140-159 \mathrm{mmHg}$ & $90-99 \mathrm{mmHg}$ \\
Stage 2 hypertension & $\geq 160 \mathrm{mmHg}$ & $\geq 100 \mathrm{mmHg}$ \\
\hline
\end{tabular}

The target population of the survey was adult hypertensive patient attending in general health camp conducted by Dhading District hospital on 26 and 27 Jestha, 2075 B.S (June 9 and 10, 2018). The sample used was all the hypertensive patient who attended the general health camp. The primary investigator trained a team of five health workers on using the survey form for data collection to ensure uniformity of data collection.

Patient who were eligible to participate in the survey were those who had been diagnosed with hypertension for $>6$ month and were 18 years and older. Pregnant, patient with psychiatry illness and those who refused to participate in survey were excluded. The doctor and the trained personnel measured the blood pressure by manual adult blood pressure measuring cuff. The blood pressure reading was taken on sitting position after rest for 5 minutes of signing up in the camp. The systolic blood pressure of more than 140 and diastolic blood pressure of more than $90 \mathrm{mmHg}$ was double checked and confirmed.

\section{SAMPLE SIZE AND STATISTICAL ANALYSIS:}

All those patients who qualified for the study were taken as a sample for the study. Total of 150 patients were analyzed by method of nonprobability purposive sampling method.
Categorical variable was analyzed using frequency and percentages. Chi-square test was used to analyze the association of risk factors with non-adherence to antihypertensive medicines. Binary logistic regression was used to quantify the strength of association of risk factors with non-adherence to anti-hypertensive medication and also to analyze effect of confounding factors between the two groups (adherent and nonadherent). All analyses were done using IBM SPSS 25.0 .

\section{RESULTS}

Total of 150 samples were analyzed; out of which $32 \% \quad(n=48)$ were complaint to medication while $68 \%(n=102)$ were in non-compliant group. Mean age was 57 years in adherent group and 52 years in non-adherent group $(\mathrm{OR}=0.96, \mathrm{p}=.01$ and $95 \%$ C.I $=0.932-0.990) .37 .5 \%$ male were in adherent group $(\mathrm{n}=26)$ and $62.3 \%$ in non-adherent group while female was $27.2 \%$ and $72.8 \%$ respectively ( $\mathrm{OR}=$ $1.512, \mathrm{p}=.292,95 \%$ C.I 0.762-3.354). Marital status, employment status and comorbid conditions, current smoker were not significantly difference between the groups. $54.5 \%$ were diabetic in adherent group while $45.5 \%$ were in non-adherent group $(\mathrm{OR}=2.634$, $\mathrm{p}<0.05,95 \%$ C.I $=0.978-7.092)$. (Table 1) 
Table 1: Frequency analysis of demographic and laboratory variables

\begin{tabular}{|c|c|c|c|c|c|c|c|c|c|}
\hline & & \multicolumn{8}{|c|}{ Compliance to medicine } \\
\hline & & \multicolumn{2}{|c|}{ Yes } & \multicolumn{2}{|r|}{ No } & \multirow{2}{*}{$\begin{array}{l}\text { Odds } \\
\text { Ratio }\end{array}$} & \multicolumn{3}{|c|}{$\begin{array}{c}\text { 95\% Confidence } \\
\text { Interval }\end{array}$} \\
\hline & & $\mathbf{N}$ & $\%$ & $\mathbf{N}$ & $\%$ & & p-value & Lower & Upper \\
\hline \multirow{2}{*}{ Gender } & Male & 26 & $37.7 \%$ & 43 & $62.3 \%$ & 1.599 & 0.214 & 0.762 & 3.354 \\
\hline & Female & 22 & $27.2 \%$ & 59 & $72.8 \%$ & & & & \\
\hline \multirow{3}{*}{ Marital status } & $\begin{array}{l}\text { Single (Reference for } \\
\text { OR) }\end{array}$ & 0 & $0.0 \%$ & 3 & $100.0 \%$ & & & & \\
\hline & Married & 47 & $32.9 \%$ & 96 & $67.1 \%$ & 0.00 & 0.99 & 0.0 & 0.0 \\
\hline & Divorced/widow & 1 & $25.0 \%$ & 3 & $75.0 \%$ & 0.0 & 0.99 & 0.0 & 0.0 \\
\hline \multirow{4}{*}{$\begin{array}{l}\text { Employment } \\
\text { status }\end{array}$} & Employed (Ref.for OR) & 13 & $31.0 \%$ & 29 & $69.0 \%$ & & & & \\
\hline & Housewife & 27 & $28.1 \%$ & 69 & $71.9 \%$ & 1.159 & 0.727 & 0.506 & 2.658 \\
\hline & Peasant & 6 & $66.7 \%$ & 3 & $33.3 \%$ & 0.167 & 0.031 & 0.033 & 0.849 \\
\hline & Others & 2 & $66.7 \%$ & 1 & $33.3 \%$ & 0.190 & 0.198 & 0.015 & 2.374 \\
\hline \multirow{2}{*}{ Diabetes } & Yes & 12 & $54.5 \%$ & 10 & $45.5 \%$ & 2.634 & 0.055 & 0.978 & 7.092 \\
\hline & No & 36 & $28.1 \%$ & 92 & $71.9 \%$ & & & & \\
\hline \multirow{2}{*}{$\begin{array}{l}\text { Current } \\
\text { smoker }\end{array}$} & Yes & 8 & $32.0 \%$ & 17 & $68.0 \%$ & 0.593 & 0.311 & 0.216 & 1.629 \\
\hline & No & 40 & $32.0 \%$ & 85 & $68.0 \%$ & & & & \\
\hline \multirow{2}{*}{ CVD } & Yes & 1 & & 3 & & 0.705 & 0.773 & 0.066 & 7.572 \\
\hline & No & 47 & & 99 & & & & & \\
\hline \multirow{4}{*}{$\begin{array}{l}\text { Comorbid } \\
\text { Condition }\end{array}$} & Not known Ref. for OR) & 31 & $29.2 \%$ & 75 & $70.8 \%$ & & & & \\
\hline & $\mathrm{DM}$ & 11 & $52.4 \%$ & 10 & $47.6 \%$ & 0.292 & 0.017 & 0.106 & 0.803 \\
\hline & High cholesterol & 5 & $26.3 \%$ & 14 & $73.7 \%$ & 1.020 & 0.973 & 0.318 & 3.277 \\
\hline & Stroke & 1 & $25.0 \%$ & 3 & $75.0 \%$ & 0.989 & 0.993 & 0.096 & 10.241 \\
\hline \multirow{2}{*}{$\begin{array}{l}\text { Family } \\
\text { hypertension }\end{array}$} & Yes & 7 & $30.4 \%$ & 16 & $69.6 \%$ & 0.709 & 0.517 & 0.250 & 2.007 \\
\hline & No & 41 & $32.3 \%$ & 86 & $67.7 \%$ & & & & \\
\hline Age in years & & 48 & $32.0 \%$ & 102 & $68.0 \%$ & 0.96 & 0.01 & 0.932 & 0.990 \\
\hline Mean Age & & 57 & & 52 & & & & & \\
\hline
\end{tabular}

Note: Abbreviation, $O R=$ odds ratio, CVD: cardiovascular disease, DM=Diabetes Mellitus

Patients were non-adherent to medication mostly because of fear to take lifelong (Chi-square test $=18.39$, $\mathrm{p}<0.05$ ) followed by preference to ayurvedic medicine/home remedy (Chi-square test $=16.201, \mathrm{p}<0.05$ ). Unaware of complication, adoption of lifestyle modification and financial weakness are other cause for nonadherence. (Table 2) 


\begin{tabular}{|c|c|c|c|c|c|c|}
\hline \multirow{3}{*}{$\begin{array}{l}\text { Reason for not taking } \\
\text { medicines }\end{array}$} & \multicolumn{4}{|c|}{ Adherence to medicine } & \multirow{2}{*}{\multicolumn{2}{|c|}{ Test statistics }} \\
\hline & \multirow{2}{*}{ Yes } & \multirow{2}{*}{ Percent } & \multirow{2}{*}{$\begin{array}{c}\text { No } \\
\text { Count } \\
\end{array}$} & \multirow{2}{*}{ Percent } & & \\
\hline & & & & & Chi-square Value & P-value \\
\hline Has to take life long & 0 & $0.0 \%$ & 31 & $30.3 \%$ & 18.39 & 0.000 \\
\hline Lifestyle modification & 0 & $0.0 \%$ & 14 & $13.7 \%$ & 7.266 & 0.007 \\
\hline $\begin{array}{l}\text { Taking Ayurvedic medicine/ } \\
\text { home remedy }\end{array}$ & 0 & $0.0 \%$ & 27 & $26.5 \%$ & 16.201 & 0.000 \\
\hline $\begin{array}{l}\text { Does not know about the } \\
\text { complication }\end{array}$ & 0 & $0.0 \%$ & 16 & $15.7 \%$ & 8.428 & 0.004 \\
\hline Financial weakness & 0 & $0.0 \%$ & 9 & $8.8 \%$ & 4.506 & 0.034 \\
\hline
\end{tabular}

\section{DISCUSSION}

Prevalence of hypertension is raising everyday all over the world and the complications associated with hypertension are also increasing. Major factor associated with uncontrolled hypertension is nonadherence to medications. This study attempted to reveal some factors associated with non-adherence to antihypertensive medications. Complaint group had $32 \%(n=48)$ of participants while $68 \%(n=102)$ were in non-compliant category. It was similar to the study of Bioma et al. in which $66.7 \%$ of participants were under non-adherence to medications group. ${ }^{16}$ In contrast, survey conducted in Seoul, Korea and Saudi Arabia showed only $13.2 \%$ and $23.6 \%$ of nonadherence respectively. ${ }^{17,18}$ Adherence to medication in these studies was significantly higher than our study.

Factors such as gender, marital status, employment status, comorbid current smoker, and comorbid conditions were not significantly different between the groups. Similarly, in the study by Bioma et al, there were no differences in medication adherence between patients who were married compared with those who were not. ${ }^{16}$ In the study done in Czech and U. K., females were more commonly non-adherent to anti-hypertensive drugs than male which matches our study results however, our results weren't statistically significant $(\mathrm{p}=0.292) .{ }^{19}$

There were $54.5 \%$ diabetic patients in adherent group and $45.5 \%$ in non-adherent group $(\mathrm{OR}=2.634, \mathrm{p}<0.05$,
95\% C.I: 0.978-7.092). This shows that the chances of non-adherence to antihypertensive medication increase if a patient is diabetic. Age was also observed to be statistically significant. Mean age was 57 years in adherent group and 52 years in non-adherent group $(\mathrm{OR}=0.96, \mathrm{p}<0.05$ and $95 \%$ C.I.: 0.932 0.990 ) indicating its significance for the adherence to medication. In Ghobain et al study, age ( $\leq 65$ years), poor monitoring, and uncontrolled blood pressure (BP $\geq 140 / 90 \mathrm{mmHg}$ ) were the predictor factors associated with nonadherence..$^{18}$ In contrast, a study conducted in UK and Czech population, age was inversely related to non-adherence. ${ }^{19}$

Patients were non-adherent to medication mostly because of fear to take medicine lifelong, followed by preference to ayurvedic medicine/home remedy. In a study by Bioma et al non-adherence was significantly more common among patients who used herbal preparation for the treatment of systemic hypertension $(p=0.014) .{ }^{16}$ Another study conducted on Lebanese population showed forgetfulness ( $p$ $=0.01)$, complicated drug regimen $(\mathrm{p}=0.001)$, and side effects $(p=0.006)$ as predictors of low adherence after multiple liner regression. ${ }^{20}$ Younger and less educated groups were less likely to adhere to prescribed medication. ${ }^{17}$ Poor knowledge about the disease and possible implications associated was reported in $80 \%$ of patients, while $66 \%$ of the patients had poor monitoring. Furthermore, financial weakness also had some association to the non-adherence to medication because of economic burden. 
Though not a part of this study but studies have demonstrated that once-daily antihypertensive medications have the highest adherence compared with twice daily or multiple daily doses, including greater adherence to the prescribed timing of doses. ${ }^{21}$ This study was a community-based survey; so, a larger inclusive study involving different communities is required before generalizing the findings. Similarly, according to a study conducted by Gupta et. al. each increase in the number of antihypertensive medications led to $85 \%$ and $77 \%$ increase in non-adherence $(\mathrm{P}<0.05)$ in the UK and $\mathrm{Czech}$ respectively. ${ }^{19}$

\section{CONCLUSIONS}

Fear to take lifelong medication was the most common reason for non-adherence; however, age and comorbid health condition like diabetes also affect significantly on adherence to medication. Proper counseling and awareness towards antihypertensive medications should be done to increase compliance to medication.

\section{REFERENCES}

1. Delacroix S, Chokka RG, Worthley SG. Hypertension: Pathophysiology and treatment. J Neurol Neurophysiol; 5. Epub ahead of print 2014. DOI: 10.4172/2155-9562.1000250.

2. CDC. High Blood Pressure Fact Sheet Data \& Statistics. Centres for Disease Control and Prevention, https://www.cdc.gov/dhdsp/data statistics/fact_sheets/fs_bloodpressure.htm (accessed 22 December 2018).

3. Dhungana RR, Pandey AR, Bista B. Prevalence and Associated Factors of Hypertension: A Community-Based Cross-Sectional Study in Municipalities of Kathmandu , Nepal. International Journal of Hypertension. Epub ahead of print 2016. DOI: $10.1155 / 2016 / 1656938$.

4. Vaidya A, Pathak RP, Pandey MR. Prevalence of hypertension in Nepalese community triples in 25 years : a repeat cross-sectional study in rural Kathmandu. Indian Heart J 2012; 64: 128-131.
5. WHO. Raised blood pressure : Global Health Observatory (GHO) data. World Health Organization, https://www.who.int/gho/en/ (2018, accessed 4 May 2019).

6. AHA. Statistical Fact Sheet 2013 Update. 2013. Epub ahead of print 2013. DOI: 10.1161/ CIR.0b013e31828124ad.

7. Shin H-Y, Lee J-Y, Kim J-E, et al. Cause-ofdeath statistics in 2016 in the Republic of Korea. J Korean Med Assoc 2018; 61: 573-584.

8. High Blood Pressure. National Heart, Lungs and Blood Institute, https://www.nhlbi.nih. gov/health-topics/high-blood-pressure (2019, accessed 3 April 2019).

9. AHA/ACC. Detailed summary from the 2017 Guideline for Prevention,Detection, Evaluation and Management of High Blood Pressure in Adults. Texas, USA, www.heart.org (2017).

10. Yang S, Jung D, Choi S. Prediction model of blood pressure control in community-dwelling hypertensive adults in Korea. Nurs Heal Sci 2010; 12: 105-12.

11. Ho PM, Bryson CL, Rumsfeld JS. Medication Adherence Its Importance in Cardiovascular Outcomes. Circulation 2009; 119: 3028-3035.

12. Osterberg L, Blaschke T. Adherence to Medication. N Engl J Med 2005; 353: 487-497.

13. Eraker S, Kirscht J, Becker M. Understanding and improving patient compliance. Ann Intern Med 1984; 100: 258-68.

14. Marcum ZA, Sevick MA, Handler SM. Medication Nonadherence: A Diagnosable and Treatable Medical Condition. JAMA 2013; 309: 2105-2106.

15. The Seventh Report of the Joint National Committee on Prevention, Detection, Evaluation, and Treatment of, https://www. nhlbi.nih.gov/health-topics/seventh-reportof-joint-national-committee-on-preventiondetection-evaluation-and-treatment-highblood-pressure (2004, accessed 3 December 2018). 
16. Boima V, Ademola AD, Odusola AO, et al. Factors Associated with Medication Nonadherence among Hypertensives in Ghana and Nigeria. Int J Hypertens; 2015. Epub ahead of print 2015. DOI: 10.1155/2015/205716.

17. Cho S, Kim J. Factors associated with nonadherence to antihypertensive medication. Nurs Heal Sci 2014; 16: 461-467.

18. Ghobain M Al, Alhashemi H, Aljama A, et al. Nonadherence to antihypertensive medications and associated factors in general medicine clinics. Patient Prefer Adherence 2016; 10: 1415-1419.

19. Gupta P, Patel P, Štrauch B, et al. Nonadherence to Antihypertensive Treatment. Risk Factors for Nonadherence to Antihypertensive Treatment. Hypertension 2017; 1113-1120.
20. Mohammad Y, Amal A, Sanaa A, et al. Evaluation of medication adherence in Lebanese hypertensive patients. J Epidemiol Glob Health 2016; 6: 157-167.

21. Flack JM, Nasser SA. Benefits of once-daily therapies in the treatment of hypertension. Vasc Health Risk Manag 2011; 7: 777-787.

\section{How to cite this article?}

Shrestha TM, Bhusal L, Raut S, Ghimire R, Shrestha P. Factors Associated with Non-Adherence to Antihypertensive Medication among Hypertensive Patients in Community. Journal of Karnali Academy of Health Sciences. 2019;2(1):53-59

Conflict of Interest: None Source of Support: None 